\title{
Evaluation of liver fibrosis with a monoexponential Rearch Paper intravoxel incoherent motion magnetic resonance imaging
}

\author{
Cuiyun Chen ${ }^{1}$, Fangfang Fu ${ }^{1}$, Jing Zhang ${ }^{2}$, Fangfang Guo ${ }^{3}$, Meiyun Wang ${ }^{1}$, Shaocheng \\ Zhu ${ }^{1}$, Dapeng Shi ${ }^{1}$ and Yuwei Tian ${ }^{2}$ \\ ${ }^{1}$ Department of Radiology, Zhengzhou University People's Hospital, Zhengzhou, Henan 450003, China \\ ${ }^{2}$ Department of Hepatobiliary Surgery, Zhengzhou University People's Hospital, Zhengzhou, Henan 450003, China \\ ${ }^{3}$ Department of Pathology, Zhengzhou University People's Hospital, Zhengzhou, Henan 450003, China \\ Correspondence to: Yuwei Tian, email: tianyuwei2011@163.com \\ Keywords: liver fibrosis; IVIM-DWl; magnetic resonance imaging; monoexponential model
}

Received: May 19, $2017 \quad$ Accepted: February 21, $2018 \quad$ Published: May 15, 2018

Copyright: Chen et al. This is an open-access article distributed under the terms of the Creative Commons Attribution License 3.0 (CC BY 3.0), which permits unrestricted use, distribution, and reproduction in any medium, provided the original author and source are credited.

\section{ABSTRACT}

To evaluate hepatic fibrosis with a monoexponential model of intravoxel incoherent motion magnetic resonance imaging, and assess the potential application value of intravoxel incoherent motion (IVIM) in diffusion-weighted imaging (IVIMDWI) in determining staging of liver fibrosis. 28 patients with hepatic fibrosis and 25 volunteers with healthy livers had IVIM examination and conventional MRI. All standard apparent diffusion coefficient (ADC) values of IVIM raw data were postprocessed off-line after completion of data collection. All regions of interest (ROIs) were manually positioned by two experienced radiologists. All values of the different fibrosis stages in the study group were compared using independent sample $t$ tests. Using ROC analysis, both AUC values of $A D C_{\text {total }}$ and $A C_{0-400-600-800}$ from study and control group were found to be between 0.8 and 1 for staging fibrosis. The mean $A D C_{\text {total }}$ and $A D C_{0-400-600-800}$ values of the liver in the study group were significantly lower than the values in the control group $(P<0.05)$. Spearman rho correlation analysis was used to determine the relationship among fibrosis stages and the $A D C_{\text {total }}$ and $A D C_{0-400-}$ ${ }_{600-800}$ in the study group. As the stage of the fibrosis increased, the values decreased. Significant differences between the two subgroups of liver fibrosis stages were found $(P<0.05)$. The monoexponential model of IVIM-DWI adopted multiple $b$ values for quantitative analysis of the water molecules diffused in the tissue. It could be used as a noninvasive and valuable method for assessment of liver fibrosis.

\section{INTRODUCTION}

Liver fibrosis is an important pathological feature of patients with chronic liver disease. It is also a serious health problem worldwide. Currently, there is no effective therapy available for liver fibrosis except the removal of underlying etiology or liver transplantation [1-3]. However, recent studies indicate that liver fibrosis is reversible, thus it is extremely important to accurately evaluate the degree of liver fibrosis and to make timely intervention measures, in order to prevent or reverse hepatic fibrosis process $[4,5]$. At present, the gold standard for evaluating the degree of liver fibrosis is liver biopsy of a percutaneous puncture Liver biopsy is an invasive operation, patients are less widely accepted and the repeatability is poor [6].

With the development of echo-planar imaging (EPI) in magnetic resonance imaging plane echo technology, intravoxel incoherent motion in diffusion weighted imaging (IVIM-DWI) technology can be applied to the abdomen to evaluate metabolic and function changes before the morphology of liver fibrosis changes [7]. 
Recently, IVIM-DWI has been suggested as a new method for noninvasive diagnosis and staging of liver fibrosis $[8,9]$. The purpose of this study is to evaluate hepatic fibrosis with a monoexponential model of intravoxel incoherent motion magnetic resonance imaging, and to assess the potential application value of IVIM-DWI in staging liver fibrosis. Our results showed that the monoexponential model of IVIM-DWI adopted multiple $b$ values for quantitative analysis of the water molecules diffused in the tissue and that it could be used as a valuable noninvasive method for assessing liver fibrosis.

\section{RESULTS}

\section{Patient information analysis}

The fibrosis stages and histological activity grades of the 38 cases are presented in Table 1 . Among the 38 patients, the fibrosis stage distributions are as follows: F0 group included 10 patients who were randomly selected from normal liver control group. F1 group included 4 patients who had mild histological activity. F2 group included 9 patients who had moderate histological activity. F3 group included 11 patients who had advanced histological activity. F4 group included 4 patients who had severe histological activity. All the standard ADC values of IVIM raw data were post-processed off-line at an ADW4.5 workstation (GE, USA) after completion of data collection (Figure 1A and 1B). Descriptive statistics, the LSD method of multiple comparison of variance for the study group and the control group were used. The mean $\mathrm{ADC}_{\text {total }}, \mathrm{ADC}_{\text {0-400-600-800 }}$ values among the right posterior hepatic lobe, right anterior hepatic lobe and medial segment of the left lobe of the liver with fibrosis and the healthy livers had no significant differences $(P>0.05)$ (Table 2).

\section{ROC analysis}

Using ROC analysis, both $\mathrm{AUC}$ values of $\mathrm{ADC}_{\text {total }}$ and $\mathrm{ADC}_{0-400-600-800}$ from all data of the study and control groups were between 0.8 and 1 for staging fibrosis (Figure 2A and 2B). Results of the ROC analysis are also summarized in Table 3.

\section{IVIM lowers $\mathrm{ADC}_{\text {total }}$ and $\mathrm{ADC}_{\text {0-400-600-800 }}$ values}

Descriptive statistics, the independent samples $t$ test for the study and control groups were used. The mean $\mathrm{ADC}_{\text {total }}$ and $\mathrm{ADC}_{0-400-600-800}$ values of the liver in the study group were significantly lower than those values in the control group $(P<0.05)$. The results are summarized in Table 4 .

\section{IVIM determines the relationship between ADC values and fibrosis stages}

Spearman rho correlation analysis was used to determine the relationship among fibrosis stages and the
$\mathrm{ADC}_{\text {total }}$ and $\mathrm{ADC}_{0-400-600-800}$ in the study group. As the stage of fibrosis progressed, the values decreased. The independent samples $t$ test was used to compare the mean values $\left(\mathrm{ADC}_{\text {total }}\right.$ and $\left.\mathrm{ADC}_{0-400-600-800}\right)$ of liver fibrosis stages between the subgroups F0-1 and F2-4, the subgroups F0-2 and F3-4, the subgroups F0-3 and F4. We found significant differences between the three subgroups of liver fibrosis stages $(P<0.05)$. The results are summarized in Table 5 .

\section{DISCUSSION}

Liver fibrosis is an early pathological indicator of chronic liver disease. It is an imbalance between fiber formation and degradation in the progression of all kinds of chronic liver diseases. Excessive quantities of collagen deposits in the liver can gradually change the stage of liver cirrhosis and even lead to hepatocellular carcinoma (HCC) $[1-3,19]$. The progression of liver fibrosis can be prevented from further development by clinical treatment. If it is not timely treated, it may progress to the decompensation period of cirrhosis, even with all kinds of complications of end-stage liver disease.

Early treatment can obviously improve the prognosis. At present, early diagnosis of hepatic fibrosis and determination of its stage is crucial for treatment. Although percutaneous liver biopsy is considered the gold standard diagnostic approach, it has several significant drawbacks. It is an invasive procedure not well accepted by patients due to the high cost of inspection, sampling bias, poor repeatability and complications. Thus, liver biopsy is not used as a routine screening method for the dynamic detection of liver fibrosis progression and treatment. In addition, when using conventional MR imaging at the stage of liver fibrosis, it is hard to find slight abnormalities or the screenings are unable to display very slight abnormal signals. Clinically, patients with liver fibrosis often had asymptomatic or mild abdominal distension under conventional MR imaging, rendering conventional MR imaging not as useful for definitive classification in liver fibrosis diagnosis [20]. The purpose of this study is to investigate the application value of the monoexponential model of IVIM-DWI in evaluation of liver fibrosis and staging, given that this technology is a new and noninvasive method that uses no contrast agent, and has good maneuverability and repeatability of inspection.

Standard ADC (the unit is $\mathrm{mm}^{2} / \mathrm{s}$ ) is the traditional ADC monoexponential model fitting b0 data and threshold value of DWI data, which can get $b$ or higher dispersion coefficient. Its basic principle is the same as the traditional ADC monoexponential model, reflecting the movement of water molecules within the organ. ADC values are the most common quantitative indicators. The calculating formula is $\mathrm{Sb} / \mathrm{S} 0=\exp (\mathrm{bADC})$. $\mathrm{S} 0$ and $\mathrm{Sb}$ represent the low and high $b$ signal value of DWI, respectively. The $\mathrm{ADC}$ values reflect the speed of the water molecules. The speed of the dispersion indicates the ADC values. 
Table 1: Distribution of various stages of fibrosis with biochemical markers of liver function

\begin{tabular}{|c|c|c|c|c|c|}
\hline Fibrosis Stage & $\begin{array}{c}\text { ALT } \\
(7-40) \text { U/L }\end{array}$ & $\begin{array}{c}\mathrm{AST} \\
(13-35) \mathrm{U} / \mathrm{L}\end{array}$ & $\begin{array}{c}\text { TP } \\
(65-85) \mathrm{g} / \mathrm{L}\end{array}$ & $\begin{array}{c}\text { ALB } \\
(40-55) \mathrm{g} / \mathrm{L}\end{array}$ & $\begin{array}{c}\text { TBIL } \\
(5-21) \mu \mathrm{M} / \mathrm{L}\end{array}$ \\
\hline F1(Mild fibrosis) & 65 & 33 & 75.1 & 45.5 & 12.2 \\
\hline F1(Mild fibrosis) & 38 & 25 & 70.4 & 44.7 & 9.2 \\
\hline F1(Mild fibrosis) & 56 & 45 & 66.3 & 44.7 & 16.9 \\
\hline F1(Mild fibrosis) & 23 & 27 & 66.3 & 42.9 & 10.3 \\
\hline F2(Moderate fibrosis) & 27 & 28 & 83.2 & 52 & 9.3 \\
\hline F2(Moderate fibrosis) & 32 & 16 & 73.1 & 45.1 & 7.8 \\
\hline F2(Moderate fibrosis) & 60 & 40 & 86.4 & 46.8 & 21.6 \\
\hline F2(Moderate fibrosis) & 86 & 81 & 75.5 & 44.9 & 8.7 \\
\hline F2(Moderate fibrosis) & 42 & 38 & 69.3 & 38.6 & 10.1 \\
\hline F2(Moderate fibrosis) & 33 & 26 & 72.2 & 41.2 & 11.2 \\
\hline F2(Moderate fibrosis) & 49 & 36 & 66.8 & 48 & 6.9 \\
\hline F2(Moderate fibrosis) & 33 & 31 & 74.2 & 41.3 & 18.9 \\
\hline F2(Moderate fibrosis) & 38 & 28 & 78.2 & 38.7 & 9.2 \\
\hline F3(Advanced fibrosis) & 26 & 27 & 80.6 & 45.9 & 16.7 \\
\hline F3(Advanced fibrosis) & 54 & 40 & 81 & 45.7 & 10.3 \\
\hline F3(Advanced fibrosis) & 47 & 37 & 60.2 & 34.9 & 17.1 \\
\hline F3(Advanced fibrosis) & 57 & 29 & 68.5 & 40.3 & 15.9 \\
\hline F3(Advanced fibrosis) & 69 & 58 & 59.6 & 32.7 & 18.7 \\
\hline F3(Advanced fibrosis) & 73 & 69 & 69.3 & 42.1 & 15.4 \\
\hline F3(Advanced fibrosis) & 63 & 49 & 70 & 49.3 & 13.1 \\
\hline F3(Advanced fibrosis) & 72 & 63 & 57.2 & 33.6 & 18.7 \\
\hline F3(Advanced fibrosis) & 69 & 45 & 66.4 & 39.2 & 12.6 \\
\hline F3(Advanced fibrosis) & 60 & 51 & 68.2 & 40.5 & 12.9 \\
\hline F3(Advanced fibrosis) & 49 & 32 & 60.3 & 39.3 & 10.6 \\
\hline F4(Cirrhosis) & 53 & 43 & 70.9 & 37.8 & 13.4 \\
\hline F4(Cirrhosis) & 57 & 49 & 69.5 & 39.2 & 15.3 \\
\hline F4(Cirrhosis) & 60 & 55 & 70.3 & 38.4 & 16.1 \\
\hline F4(Cirrhosis) & 58 & 50 & 69.6 & 39 & 14.7 \\
\hline
\end{tabular}

The ADC value is influenced by water molecules' diffuse and capillary perfusion, which is closely related to its $b$ values. If the $b$ value is $>200 \mathrm{~s} / \mathrm{mm}^{2}$, the result mainly reflects the dispersion of the water molecules; if the $b$ value is $<200 \mathrm{~s} / \mathrm{mm}^{2}$, the result mainly reflects the blood perfusion of the situation. In this study, the standard ADC values (namely $\mathrm{ADC}_{\text {total }}$ ) by $7 b$ values and (namely $\mathrm{ADC}_{0 \text { - }}$ 400-600-800 ) by $4 b$ values were according to the formula of $\mathrm{Sb} / \mathrm{S} 0=\exp (\mathrm{bADC})$, respectively. Thus, it is easy to understand from the formula. While ADC values are not only reflected by distribution of the $b$ value $\left(>200 \mathrm{~s} / \mathrm{mm}^{2}\right.$ or $<200 \mathrm{~s} / \mathrm{mm}^{2}$ ), they can be simultaneously affected by water molecules' diffuse and capillary perfusion. Since $\mathrm{ADC}$ values were related to the number of $b$ values, the more the values of $b$ that were chosen, the more objective and accurate were the measured results. Using ROC curve analysis, we concluded that the mean values of $\mathrm{ADC}_{\text {total }}$ and $\mathrm{ADC}_{0-400-00-800}$ for diagnosis of liver fibrosis by area under the ROC curve were 0.855 and 0.939 , respectively. $\mathrm{ADC}_{0-400-00-800}$ showed better diagnosis ability than $\mathrm{ADC}_{\text {total }}$ in the diagnosis of liver fibrosis. When taking a certain critical value of diagnosis, the results showed sensitivity, specificity, false positives and false negatives of $\mathrm{ADC}_{0-400}$ 00-800 to be higher than $\mathrm{ADC}_{\text {total }}$.

Liver fibrosis is the main collagen in the formation of the extracellular matrix (ECM) caused by excessive deposition, which results in significant proton decreases $[21,22]$. Therefore, if it has fibrotic distortion within the hepatic lobule of organ's structure, the collagen deposition of the extracellular matrix will limit the movement of water molecules. The result can lead to the lower ADC values of liver fibrosis and liver cirrhosis, rather than the 
higher values found in a normal liver [23-26]. According to reports in the literature [27], experimenters chose a single $b$ value of $>200 \mathrm{~s} / \mathrm{mm}^{2}$ in traditional DWI-MRI which could mainly reflect water molecules diffused in the organ. The ability of DWI-MRI in diagnosing liver fibrosis was only reached at a medium level. However, in recent years, increasing number of reports in the literature adopted multiple $b$ values, which were then compared to different $b$ values in the diagnosis of liver fibrosis. VaziriBozorg et al. [13] selected 11 cases with normal livers as the control group and 33 patients with hepatitis $\mathrm{B}$ or $\mathrm{C}$ as the study group, using the $b$ values of $0-500,0-700$, $0-1000 \mathrm{~s} / \mathrm{mm}^{2}$. The results demonstrated that using the $b$ value of $500 \mathrm{~s} / \mathrm{mm}^{2}$ in the diagnosis of liver fibrosis was significantly better than $b$ values of $700 \mathrm{~s} / \mathrm{mm}^{2}$ and 1000 $\mathrm{s} / \mathrm{mm}^{2}$. Ozkurt $\mathrm{H}$ et al. [28] studied 24 patients with liver fibrosis and 22 cases with healthy subjects. The $b$ values were set at $250 \mathrm{~s} / \mathrm{mm}^{2}, 500 \mathrm{~s} / \mathrm{mm}^{2}$ and $750 \mathrm{~s} / \mathrm{mm}^{2}$. Only the $750 \mathrm{~s} / \mathrm{mm}^{2} b$ value was able to accurately diagnosis liver fibrosis. Therefore, according to the formula above, the ADC value of the single $b$ value was not sufficiently accurate to measure water molecules in liver tissue.
Yamada et al. [29] first reported IVIM-MRI technology in the liver. The IVIM technology was used with $4 b$ values $\left(30,300,900,1100 \mathrm{~s} / \mathrm{mm}^{2}\right)$; there was no significant difference between normal livers and those with cirrhosis. Luciani et al. [30] analyzed 37 cases (12 cases of patients with cirrhosis and 25 cases of healthy livers), and assessed the difference between livers with cirrhosis and normal livers by IVIM ( $b$ values: $0,10,20,30,50,80$, $100,200,400,800 \mathrm{~s} / \mathrm{mm}^{2}$ ). The ADC values of the liver cirrhosis group were significantly lower than those of the normal liver group $\left(1.23 \times 10^{-3}\right.$ vs. $\left.1.39 \times 10^{-3} \mathrm{~mm}^{2} / \mathrm{s}\right)$.

Patel et al.[11] studied 16 cases without, and 14 cases with, liver cirrhosis, which adopted IVIM technology and chose $9 b$ values $(0,50,100,150,200,300,500,700$, $1000 \mathrm{~s} / \mathrm{mm}^{2}$ ). The ADC values and real values of water molecules were significantly lower in the liver cirrhosis group than those in the no cirrhosis group $\left(1.41 \times 10^{-3} \mathrm{vs}\right.$. $1.73 \times 10^{-3} \mathrm{~mm}^{2} / \mathrm{s}$ and $1.04 \times 10^{-3}$ vs. $\left.1.17 \times 10^{-3} \mathrm{~mm}^{2} / \mathrm{s}\right)$. Although in recent years, IVIM-MRI technology was used in research of chronic liver disease with values both less and more than $200 \mathrm{~s} / \mathrm{mm}^{2}$, in this study the values of $\mathrm{ADC}_{\text {total }}$ and $\mathrm{ADC}_{0-400-600-800}$ of the liver fibrosis group were
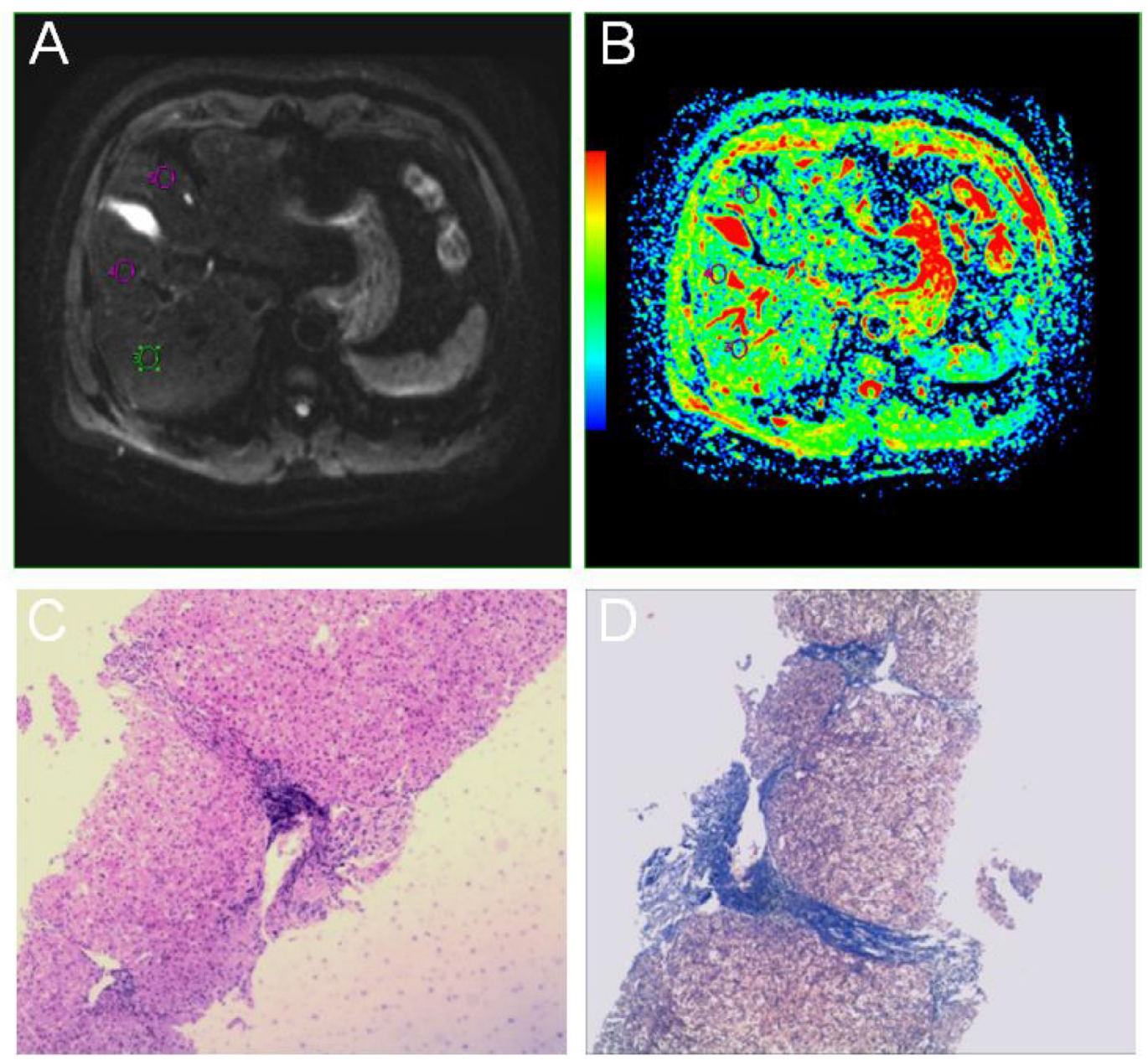

Figure 1: A 40-year-old male patient with a history of hepatitis. (A, B) Multiple b DWIs, standard ADC. (C, D) HE staining with microscopic observation $(\times 40)$ and Masson staining with microscopic observation $(\times 40)$, respectively. 
Table 2: Multiple comparison analysis of variance among NL and LF segments

\begin{tabular}{|c|c|c|c|c|}
\hline \multirow[b]{2}{*}{ Parameters } & $\mathbf{R P}$ & $\mathbf{R A}$ & LM & \multirow{2}{*}{$\begin{array}{c}P \text { values from } \\
\text { multiple comparisons }\end{array}$} \\
\hline & $\begin{array}{c}\text { Mean } \pm \text { SD } \\
\left(\times 10^{-3} \mathrm{~mm}^{2} / \mathrm{s}\right)\end{array}$ & $\begin{array}{c}\text { Mean } \pm \text { SD } \\
\left(\times 10^{-3} \mathrm{~mm}^{2} / \mathbf{s}\right)\end{array}$ & $\begin{array}{c}\text { Mean } \pm \text { SD } \\
\left(\times 10^{-3} \mathrm{~mm}^{2} / \mathrm{s}\right)\end{array}$ & \\
\hline $\mathrm{NL}-\mathrm{ADC}_{\text {total }}$ & $1.36 \pm 0.29$ & $1.31 \pm 0.21$ & $1.40 \pm 0.22$ & $0.538^{*}, 0.241^{\dagger}, 0.576^{\star}$ \\
\hline NL-ADC ${ }_{0-400-600-800}$ & $1.23 \pm 0.04$ & $1.22 \pm 0.04$ & $1.22 \pm 0.03$ & $0.179^{*}, 1.000^{\dagger}, 0.179$ \\
\hline LF-ADC total & $1.10 \pm 0.17$ & $1.10 \pm 0.27$ & $1.10 \pm 0.26$ & $0.952^{*}, 0.971^{\dagger}, 0.981^{\star}$ \\
\hline LF-ADC ${ }_{0-400-600-800}$ & $1.04 \pm 0.15$ & $1.02 \pm 0.18$ & $1.03 \pm 0.17$ & $0.582^{*}, 0.859^{\dagger}, 0.709^{*}$ \\
\hline
\end{tabular}

$\mathrm{RP}=$ right posterior hepatic lobe; $\mathrm{RA}=$ right anterior hepatic lobe; $\mathrm{LM}=$ medial segment of the left lobe; $\mathrm{NL}=\mathrm{normal}$ liver; LF = liver fibrosis; ${ }^{*}=\mathrm{RP}$ vs RA; ${ }^{\dagger}=\mathrm{RA}$ vs LM; $*=\mathrm{RP}$ vs LM.

significantly lower than those of the normal liver group, especially the $\mathrm{ADC}_{0-400-600-800}$ values. The reasons for the differences between the results of our study and those of Yamada et al. and Luciani et al. were the number of $b$ values selected and the $b$ value distribution, as well as our selected cases of hepatic fibrosis and its different stages.

With the increased progression of liver fibrosis, the accumulation of proteins in the extracellular matrix can also gradually increase. Our results verified that the mean values of $\mathrm{ADC}_{\text {total }}$ and $\mathrm{ADC}_{0-400-600-800}$ decreased as fibrosis scores increased. This data was consistent with the study by Taouli et al. [31] and Zeng Y [32], who confirmed a significant correlation between liver fibrosis staging and $\mathrm{ADC}$ values. For further comparison, we found significant differences between the subgroups F0-1 and F2-4, and between the subgroups F0-2 and F3-4, and between the subgroups F0-3 and F4 $(P<0.05)$ in liver fibrosis. In this study, we included 4 patients for both F1 and F4 groups because patients at F1 stage are hard to be detected due to absence of symptoms, while patients at F4 stage could be bleeding after liver biopsy and poor treatment by clinical

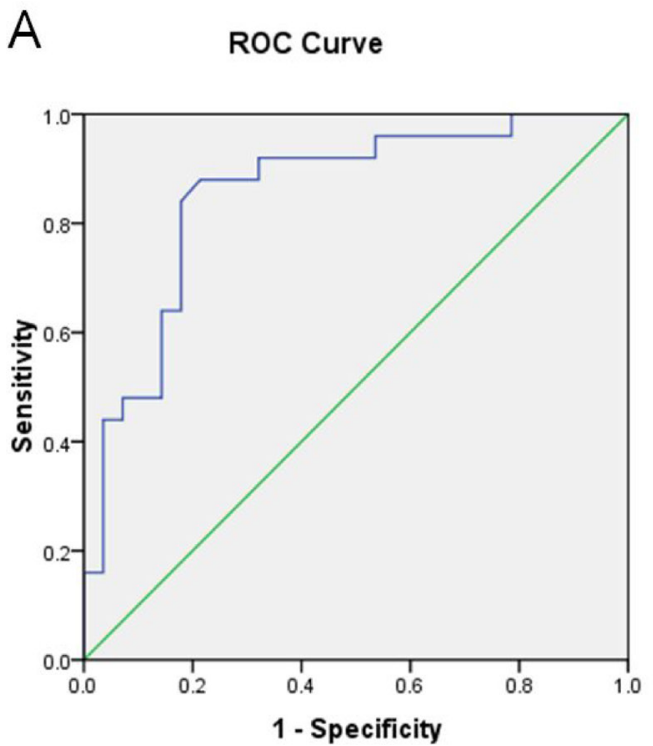

medication. Clinically, high accuracy in the diagnosis of fibrosis with stage 2 or less could be acceptable for identifying candidates for treatment to prevent progression [1-3]. However, identifying fibrosis at stage 3 or greater is essential because patients with advanced fibrosis or cirrhosis should be screened for portal hypertension and hepatocellular carcinoma [33].

Our study had several limitations. First, the results were limited by the sample size, especially the small number of patients with fibrosis stage F1 and F4. A large number of patients in each fibrosis stage need to be compared in future study. Secondly, in this study, we analyzed various etiologies of liver fibrosis which could have a certain difference among diverse etiologies, thus we will study the etiology of liver fibrosis in our next step. Thirdly, we did not analyze the deposition of iron and fat in liver fibrosis and we do not know whether they would affect the values of $\mathrm{ADC}_{\text {total }}$ and $\mathrm{ADC}_{0-400-600-800^{\circ}}$. Fourthly, ADC values are composed of water diffusion and blood microcirculation perfusion, which are hard to be distinguished and could affect ADC values in liver

B

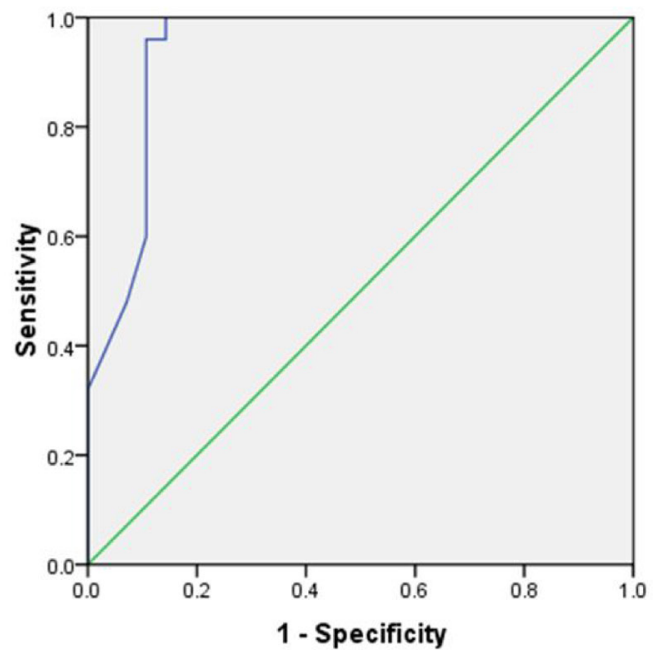

Figure 2: Results of receiver operator characteristic $\left(\right.$ ROC) analysis for study and control groups. $(A) \mathrm{ADC}_{\text {total }}(\mathrm{B}) \mathrm{ADC}_{0-}$ $400-600-800^{\circ}$ 
Table 3: ROC analysis of $\mathrm{ADC}_{\text {total }}$ and $\mathrm{ADC}_{0-400-600-800}$ for the diagnosis of fibrosis

\begin{tabular}{lcc}
\hline Parameters & ADC $_{\text {total }}$ & ADC $_{\mathbf{0 - 4 0 0 - 6 0 0 - 8 0 0}}$ \\
\hline AUC & 0.855 & 0.939 \\
$95 \%$ CI & $0.750-0.960$ & $0.871-1.007$ \\
Cutoff values & 1.240 & 1.173 \\
Sensitivity (\%) & 88 & 100 \\
Specificity (\%) & 78.6 & 85.7 \\
PPV (\%) & 80.4 & 87.5 \\
NPV (\%) & 86.8 & 100 \\
\hline
\end{tabular}

Table 4: Comparison of the mean $\mathrm{ADC}_{\text {total }}$ and $\mathrm{ADC}_{0-400-600-800}$ values

\begin{tabular}{lccccc}
\hline \multicolumn{1}{c}{ Parameters } & $\begin{array}{c}\text { Control Group } \\
\left(\times \mathbf{1 0}-\mathbf{~} \mathbf{~ m m}^{2} / \mathbf{s}\right)\end{array}$ & $\mathbf{9 5 \%} \mathbf{C I}$ & $\begin{array}{c}\text { Study Group } \\
\left(\times \mathbf{1 0}^{-\mathbf{3}} \mathbf{~ m m}^{2} / \mathbf{s}\right)\end{array}$ & $\mathbf{9 5 \%} \mathbf{C I}$ & $\boldsymbol{P}$ value by $\boldsymbol{t}$ test \\
\hline $\mathrm{ADC}_{\text {total }}$ & $1.36 \pm 0.16$ & $1.29-1.42$ & $1.10 \pm 0.20$ & $1.02-1.17$ & 0.000 \\
$\mathrm{ADC}_{0-400-600-800}$ & $1.22 \pm 0.02$ & $1.21-1.23$ & $1.03 \pm 0.16$ & $0.96-1.09$ & 0.000 \\
\hline
\end{tabular}

Table 5: Comparison of mean values between fibrosis stages ( $t$ test)

\begin{tabular}{lccccccccc}
\hline & F0-1 VS F2-4 & values & & F0-2 VS F3-4 & values & & F0-3 VS F4 & values \\
\hline Parameters & $\begin{array}{c}\text { Mean } \pm \text { SD } \\
\left(\times \mathbf{1 0}^{-3} \mathbf{m m}^{2} / \mathbf{s}\right)\end{array}$ & $\begin{array}{c}\text { Mean } \pm \text { SD } \\
\left(\times \mathbf{1 0}^{-3} \mathbf{m m}^{2} / \mathbf{s}\right)\end{array}$ & $\begin{array}{c}\boldsymbol{P} \\
\text { values }\end{array}$ & $\begin{array}{c}\text { Mean } \pm \mathbf{S D} \\
\left(\times \mathbf{1 0}^{-3} \mathbf{m m}^{2} / \mathbf{s}\right)\end{array}$ & $\begin{array}{c}\text { Mean } \pm \mathbf{S D} \\
\left(\times \mathbf{1 0}^{-3} \mathbf{m m}^{2} / \mathbf{s}\right)\end{array}$ & $\begin{array}{c}\boldsymbol{P} \\
\text { values }\end{array}$ & $\begin{array}{c}\text { Mean } \pm \text { SD } \\
\left(\times \mathbf{1 0}^{-3} \mathbf{m m}^{2} / \mathbf{s}\right)\end{array}$ & $\begin{array}{c}\text { Mean } \pm \mathbf{S D} \\
\left(\times \mathbf{1 0}^{-3} \mathbf{m m}^{2} / \mathbf{s}\right)\end{array}$ & $\begin{array}{c}\boldsymbol{P} \\
\mathbf{v a l u e s}\end{array}$ \\
\hline $\mathrm{ADC}_{\text {total }}$ & $1.34 \pm 0.20$ & $1.08 \pm 0.19$ & 0.001 & $1.27 \pm 0.20$ & $1.04 \pm 0.20$ & 0.002 & $1.22 \pm 0.19$ & $0.84 \pm 0.21$ & 0.001 \\
$\mathrm{ADC}_{0-400-600-800}$ & $1.20 \pm 0.08$ & $1.01 \pm 0.17$ & 0.000 & $1.16 \pm 0.09$ & $0.95 \pm 0.18$ & 0.000 & $1.13 \pm 0.09$ & $0.68 \pm 0.14$ & 0.000 \\
\hline
\end{tabular}

fibrosis. Our future work will test IVIM parameters with biexponential model in liver fibrosis.

\section{MATERIALS AND METHODS}

\section{Study design and patient population}

From October 2012 to June 2013, thirty patients with chronic hepatitis were prospectively enrolled from outpatients and inpatients of the Department of Digestion in our hospital. All participants had an IVIM examination and conventional MRI. Among them, five patients were excluded from the study because of no liver biopsy, poor images, bad cooperation or other possible suspicious lesions found on conventional MRI findings. Finally, twenty-eight patients (23 males and 5 females, ages ranging from 25 to 73 years with a mean age of $43.8 \pm 1.1$ years) were enrolled into our study. Among the 28 patients, there were 18 cases of hepatitis $\mathrm{B}$, one case of hepatitis $\mathrm{C}$, one case of alcoholic hepatitis, and unknown causes in eight patients with elevated transaminase levels. All the patients had liver biopsies within one month of the MRI. Clinically, nine patients had slight abdominal distension and sixteen patients were asymptomatic. Twenty-five volunteers (15 males and 10 females, ages ranging from 25 to 57 years with a mean age of $38.9 \pm 1.3$ years who had no liver diseases or abnormal liver function) were used as the control group. The normality of volunteers was checked by biochemical testing of blood. All participants were given informed consent. All participants were given informed consent and the study was approved by the Ethics Committee of the People's Hospital of Zhengzhou University.

\section{Examination and post processing}

All participants were imaged with a 3.0T MR unit (GE Medical System, Discovery MR750, USA) with an 8-channel torso SD array body coil. Conventional MRI included axial T1-weighted spin echo (TR $180 \mathrm{~ms}$, TE $2.1 \mathrm{~ms}$ ), T2-weighted spin echo (TR $4286 \mathrm{~ms}$, TE $88.1 \mathrm{~ms}$ ), and coronal T2-weighted spin echo (TR $8571 \mathrm{~ms}$, TE $88.8 \mathrm{~ms}$ ). IVIM examination data were obtained adopting DW EPI with respiratory-triggered sequence (TR, 12000 ms; TE, $62.1 \mathrm{~ms}$; Scan matrix, $160 \times 192$; number of signals acquired, seven $b$ values, $0,50,100,200,400,600,800$ $\mathrm{s} / \mathrm{mm}^{2}$; FOV, $360 \times 324 \mathrm{~mm}$; section thickness, $3 \mathrm{~mm}$; and interstice gap, $1 \mathrm{~mm}$ ). All regions of interest (ROIs) were manually positioned by two experienced radiologists who were in agreement with DW EPI diffusion images on the workstation for all $b$ values. When we selected all the $b$ values $\left(0,50,100,200,400,600,800 \mathrm{~s} / \mathrm{mm}^{2}\right)$, we got the standard ADC value of the monoexponential model, namely $\mathrm{ADC}_{\text {total }}$. When we selected the four $b$ values $(0$, $400,600,800 \mathrm{~s} / \mathrm{mm}^{2}$ ), we got the standard ADC value of the monoexponential model, namely $\mathrm{ADC}_{0-400-600-800}$. Both 
values were calculated according to the formula $[10,11]$ of $\mathrm{Sb} / \mathrm{S} 0=\exp (\mathrm{bADC})$ respectively. ROIs (about $150 \mathrm{~mm}^{2}$ ) $[12,13]$ were positioned in the right posterior hepatic lobe, the right anterior hepatic lobe, the medial segment of the left lobe of each person, respectively. Care was taken to avoid large vessels, blurred regions, and any focal lesions. The values obtained from each person were calculated by averaging the three ROI measurements.

\section{Histopathology}

Within 1 month of MRI, all patients with liver fibrosis were punctured. The stage of fibrosis was determined based on the histopathology of an 18-gauge ultrasound guided core biopsy liver sample [14-17], taken from the posterior lobe of the liver. Two experienced pathologists (with 15 years and 6 years of working experience in abdominal diagnosis) scored pathological specimens (Figure 1C and 1D) using the Knodell scoring system. The METAVIR semi-quantitative scoring system was used in the histopathologic determination of the stage of fibrosis. Fibrosis was staged on an F scale of $0-4$, as follows: F0, indicating no fibrosis; F1, portal fibrosis without septa; F2, bridging fibrosis with few septa; F3, numerous septa without cirrhosis; and F4, early cirrhosis [18].

\section{Statistical analysis}

The data were analyzed with the SPSS 16.0 software. Descriptive statistics were used for the study and the control groups. All data were presented as means \pm SD. The LSD method of multiple comparison analysis of variance was used for calculating the mean $\mathrm{ADC}_{\text {total }}$ and $\mathrm{ADC}_{0-400-600-800}$ values obtained from the right posterior hepatic lobe, right anterior hepatic lobe and medial segment of the left lobe of the study group and the control group, respectively. ROC curves were used when calculating the AUC, sensitivity, specificity and 95\% confidence intervals of the study and control groups. Positive predictive values (PPV) and negative predictive values (NPV) were calculated. To compare the mean values $\left(\mathrm{ADC}_{\text {total }}\right.$ and $\left.\mathrm{ADC}_{0-400-600-800}\right)$ of the study and control groups, independent sample $t$ tests and 95\% confidence intervals were used. Spearman rank correlation analysis was conducted to examine the relationship among all the values and fibrosis stages. All values among the different fibrosis stages (subgroups F0-1 and F2-4, subgroups F0-2 and F3-4, subgroups F0-3 and F4) were compared in the study group by using independent sample $t$ tests. A $P$-value $<0.05$ was considered to indicate a significant difference.

\section{CONFLICTS OF INTEREST}

The authors have declared that no competing interests exist.

\section{FUNDING}

This work was supported by National Natural Science Foundation of China (No. 81271565 and No. 81271534).

\section{REFERENCES}

1. Afdhal NH. Diagnosing fibrosis in hepatitis C: is the pendulum swinging from biopsy to blood tests? Hepatology. 2003; 37:972-4. https://doi.org/10.1053/jhep.2003.50223.

2. Rosenberg WM, Voelker M, Thiel R, Becka M, Burt A, Schuppan D, Hubscher S, Roskams T, Pinzani M, Arthur MJ, and European Liver Fibrosis Group. Serum markers detect the presence of liver fibrosis: a cohort study. Gastroenterology. 2004; 127:1704-13.

3. Zhu NY, Chen KM, Chai WM, Li WX, Du LJ. Feasibility of diagnosing and staging liver fibrosis with diffusion weighted imaging. Chin Med Sci J. 2008; 23:183-6.

4. Atta HM. Reversibility and heritability of liver fibrosis: Implications for research and therapy. World J Gastroenterol. 2015; 21:5138-48. https://doi.org/10.3748/ wjg.v21.i17.5138.

5. Sun M, Kisseleva T. Reversibility of liver fibrosis. Clin Res Hepatol Gastroenterol. 2015; 39:S60-3. https:/doi. org/10.1016/j.clinre.2015.06.015.

6. Sherman KE, Goodman ZD, Sullivan ST, Faris-Young S, and GILF Study Group. Liver biopsy in cirrhotic patients. Am J Gastroenterol. 2007; 102:789-93. https://doi. org/10.1111/j.1572-0241.2007.01110.x.

7. Yoon JH, Lee JM, Baek JH, Shin CI, Kiefer B, Han JK, Choi BI. Evaluation of hepatic fibrosis using intravoxel incoherent motion in diffusion-weighted liver MRI. J Comput Assist Tomogr. 2014; 38:110-6. https://doi. org/10.1097/RCT.0b013e3182a589be.

8. Zhang B, Liang L, Dong Y, Lian Z, Chen W, Liang C, Zhang S. Intravoxel Incoherent Motion MR Imaging for Staging of Hepatic Fibrosis. PLoS One. 2016; 11:e0147789. https://doi.org/10.1371/journal.pone.0147789.

9. Chung SR, Lee SS, Kim N, Yu ES, Kim E, Kuhn B, Kim IS. Intravoxel incoherent motion MRI for liver fibrosis assessment: a pilot study. Acta Radiol. 2015; 56:1428-36. https://doi.org/10.1177/0284185114559763.

10. Le Bihan D, Breton E, Lallemand D, Aubin ML, Vignaud J, Laval-Jeantet M. Separation of diffusion and perfusion in intravoxel incoherent motion MR imaging. Radiology. 1988; 168:497-505. https://doi.org/10.1148/ radiology.168.2.3393671.

11. Patel J, Sigmund EE, Rusinek H, Oei M, Babb JS, Taouli B. Diagnosis of cirrhosis with intravoxel incoherent motion diffusion MRI and dynamic contrast-enhanced MRI alone and in combination: preliminary experience. J Magn Reson Imaging. 2010; 31:589-600. https://doi.org/10.1002/ jmri.22081. 
12. Filipe JP, Curvo-Semedo L, Casalta-Lopes J, Marques MC, Caseiro-Alves F. Diffusion-weighted imaging of the liver: usefulness of ADC values in the differential diagnosis of focal lesions and effect of ROI methods on ADC measurements. MAGMA. 2013; 26:303-12. https://doi. org/10.1007/s10334-012-0348-1.

13. Vaziri-Bozorg SM, Ghasemi-Esfe AR, Khalilzadeh O, Mazloumi M, Nassiri-Toosi M, Ghanaati H, RokniYazdi H. Diffusion-weighted magnetic resonance imaging for diagnosis of liver fibrosis and inflammation in chronic viral hepatitis: the performance of low or high $B$ values and small or large regions of interest. Can Assoc Radiol J. 2012; 63:304-11. https://doi.org/10.1016/j.carj.2011.04.002.

14. Colloredo G, Guido M, Sonzogni A, Leandro G. Impact of liver biopsy size on histological evaluation of chronic viral hepatitis: the smaller the sample, the milder the disease. $\mathrm{J}$ Hepatol. 2003; 39:239-44.

15. Bedossa P, and The French METAVIR Cooperative Study Group. Intraobserver and interobserver variations in liver biopsy interpretation in patients with chronic hepatitis C. Hepatology. 1994; 20:15-20.

16. Bedossa P, Dargere D, Paradis V. Sampling variability of liver fibrosis in chronic hepatitis C. Hepatology. 2003; 38:1449-57. https://doi.org/10.1016/j.hep.2003.09.022.

17. Guido M, Rugge M. Liver biopsy sampling in chronic viral hepatitis. Semin Liver Dis. 2004; 24:89-97. https://doi. org/10.1055/s-2004-823103.

18. Knodell RG, Ishak KG, Black WC, Chen TS, Craig R, Kaplowitz N, Kiernan TW, Wollman J. Formulation and application of a numerical scoring system for assessing histological activity in asymptomatic chronic active hepatitis. Hepatology. 1981; 1:431-5.

19. Ismail $\mathrm{MH}$, Pinzani $\mathrm{M}$. Reversal of liver fibrosis. Saudi J Gastroenterol. 2009; 15:72-9. https://doi. org/10.4103/1319-3767.45072.

20. Burroughs AK, Cholongitas E. Non-invasive tests for liver fibrosis: encouraging or discouraging results? J Hepatol. 2007; 46:751-5. https://doi.org/10.1016/j.jhep.2007.02.017.

21. Friedman SL. Molecular regulation of hepatic fibrosis, an integrated cellular response to tissue injury. J Biol Chem. 2000; 275:2247-50.

22. Wynn TA. Cellular and molecular mechanisms of fibrosis. J Pathol. 2008; 214:199-210. https://doi.org/10.1002/ path. 2277 .

23. Lewin M, Poujol-Robert A, Boelle PY, Wendum D, Lasnier E, Viallon M, Guechot J, Hoeffel C, Arrive L, Tubiana JM, Poupon R. Diffusion-weighted magnetic resonance imaging for the assessment of fibrosis in chronic hepatitis C. Hepatology. 2007; 46:658-65. https://doi. org/10.1002/hep.21747.
24. Sijens PE. Parametric exploration of the liver by magnetic resonance methods. Eur Radiol. 2009; 19:2594-607. https:// doi.org/10.1007/s00330-009-1470-y.

25. Girometti R, Furlan A, Bazzocchi M, Soldano F, Isola M, Toniutto P, Bitetto D, Zuiani C. Diffusion-weighted MRI in evaluating liver fibrosis: a feasibility study in cirrhotic patients. Radiol Med. 2007; 112:394-408. https://doi. org/10.1007/s11547-007-0149-1.

26. Girometti R, Furlan A, Esposito G, Bazzocchi M, Como G, Soldano F, Isola M, Toniutto P, Zuiani C. Relevance of $b$-values in evaluating liver fibrosis: a study in healthy and cirrhotic subjects using two single-shot spin-echo echo-planar diffusion-weighted sequences. J Magn Reson Imaging. 2008; 28:411-9. https://doi.org/10.1002/ jmri.21461.

27. Bonekamp S, Torbenson MS, Kamel IR. Diffusionweighted magnetic resonance imaging for the staging of liver fibrosis. J Clin Gastroenterol. 2011; 45:885-92. https:// doi.org/10.1097/MCG.0b013e318223bd2c.

28. Ozkurt H, Keskiner F, Karatag O, Alkim C, Erturk SM, Basak M. Diffusion Weighted MRI for Hepatic Fibrosis: Impact of $b$-Value. Iran J Radiol. 2014; $11: \mathrm{e} 3555$. https:// doi.org/10.5812/iranjradiol.3555.

29. Yamada I, Aung W, Himeno Y, Nakagawa T, Shibuya H. Diffusion coefficients in abdominal organs and hepatic lesions: evaluation with intravoxel incoherent motion echoplanar MR imaging. Radiology. 1999; 210:617-23. https:// doi.org/10.1148/radiology.210.3.r99fe17617.

30. Luciani A, Vignaud A, Cavet M, Nhieu JT, Mallat A, Ruel L, Laurent A, Deux JF, Brugieres P, Rahmouni A. Liver cirrhosis: intravoxel incoherent motion MR imaging-pilot study. Radiology. 2008; 249:891-9. https://doi. org/10.1148/radiol.2493080080.

31. Taouli B, Tolia AJ, Losada M, Babb JS, Chan ES, Bannan MA, Tobias H. Diffusion-weighted MRI for quantification of liver fibrosis: preliminary experience. AJR Am J Roentgenol. 2007; 189:799-806. https://doi. org/10.2214/AJR.07.2086.

32. Zeng Y, Zhao JN, Wu W, Chen WJ, Ma Y, Leng Z. [Establish ment of liver fibrosis in rabbit model and quantitative study on hepatic perfusion with dynamic whole-liver 3D MR imaging]. [Article in Chinese]. Zhonghua Gan Zang Bing Za Zhi. 2009; 17:350-53.

33. Ghany MG, Strader DB, Thomas DL, Seeff LB, and American Association for the Study of Liver Diseases. Diagnosis, management, and treatment of hepatitis $\mathrm{C}$ : an update. Hepatology. 2009; 49:1335-74. https://doi.org/10.1002/ hep.22759. 